\title{
Residue dissipation, degradation dynamics, and dietary risk assessment of mandipropamid in ginseng under field application
}

\section{Zhiguang Hou}

Jilin Agricultural University

\section{Xingang Hou}

Jilin Agricultural University

Liping Wei

Jilin Agricultural University

\section{Zhanwen Cao}

Jilin Agricultural University

\section{Zhou Lu}

Jilin Agricultural University

\section{Hanjv Liu}

Jilin Agricultural University

Zhongbin Lu ( $\triangle$ luzong1979@aliyun.com )

Jilin Agricultural University

\section{Research Article}

Keywords: mandipropamid, ginseng, HPLC-MS/MS, dissipation, dietary risk assessment

Posted Date: August 31st, 2022

DOI: https://doi.org/10.21203/rs.3.rs-1202328/v2

License: (c) (i) This work is licensed under a Creative Commons Attribution 4.0 International License.

Read Full License 

mandipropamid in ginseng under field application

3 Running title: Degradation and assessment of mandipropamid in ginseng

4 Zhiguang Hou*, Xingang Hou*, Liping Wei, Zhanwen Cao, Zhou Lu, Hanju Liu, Zhongbin Lu

5 College of Plant Protection, Jilin Agricultural University, Changchun, Jilin, China

$6 \quad *$ These authors contributed equally to this work.

7 Corresponding author: Zhongbin Lu, College of Plant Protection, Jilin Agricultural University,

8 Changchun, China; Phone: +86 (431) 84510942; Fax: +86 (431) 84510942; E-mail:

9 luzong1979@aliyun.com

10 Abbreviations

11 
12 Abstract: Mandipropamid, a new fungicide for oomycete disease, has a strong effect

13 on the blight of many crops and has been registered for the treatment of ginseng blight

14 in China. However, no maximum residue limit (MRL) of mandipropamid has been

15 identified for ginseng, and there have been few related studies. We established and

16 verified the analysis method of mandipropamid in ginseng using high-performance

17 liquid chromatography-tandem mass spectrometry. The method has good linearity and

18 accuracy in the range of $0.002-0.5 \mathrm{mg} / \mathrm{kg}$. The average recovery of mandipropamid

19 was $87.4-101.6 \%$, and the standard deviation was 1.1-10.1. Mandipropamid in

20 ginseng plants and soil rapidly degraded following first-order kinetics models. The

21 degradation dynamics showed that the half-life of mandipropamid in ginseng plant

22 and soil was 13.8-28.0 and 9.8-27.4 d, respectively. After the recommended dose of

23 mandipropamid was applied once, the residual content of mandipropamid in fresh

24 ginseng, dried ginseng, red ginseng, ginseng plant, and ginseng soil was $<0.01-0.185$,

$25<0.01-0.265,0.085-1.544,0.075-4.800$, and $<0.01-0.014 \mathrm{mg} / \mathrm{kg}$, respectively. The

26 dietary risk assessment of mandipropamid on ginseng showed that the risk quotient

27 value was far less than $100 \%$, indicating that the recommended dose of

28 mandipropamid does not cause unacceptable risks to humans. After the recommended

29 dose of mandipropamid was applied once, it did not cause unacceptable risks to

30 humans. This study not only provides a reasonable spray dosage of mandipropamid to

31 ginseng, but also offers a reference for the establishment of MRLs in China. 
32 Keywords: mandipropamid; ginseng; HPLC-MS/MS; dissipation; dietary risk

33 assessment

34 


\section{Introduction}

Ginseng is the dried root and rhizome of Panax ginseng C.A.Mey (Zhang et al.,

37 2021). As the largest ginseng planting and production country in the world, China has a long history of medicinal use of ginseng. Ginseng plays an important role in regulating human health and treating different diseases (Fan et al., 2020) through its antitumor, antioxidation, and antidiabetic properties (Park et al., 2017). The growth cycle of ginseng is relatively long, usually 4-6 years for garden ginseng and more than 15 years for forest ginseng. During the long growth cycle, the occurrence of diseases affects the quality of ginseng, which causes significant economic losses to ginseng farmers and affects the import and export of ginseng. Therefore, fungicides must be used to prevent diseases during the planting process. However, due to the irregular use of pesticides, excessive pesticide residues can be found in ginseng.

Mandipropamid is a new fungicide for oomycete diseases (Tang et al., 2011), which is the first commercial amygdalinamide compound with the chemical name of 2-(4chlorophenyl)-n-[2-(3-methoxy-4-prop-2-ynynloxy-phenyl)-ethyl]-2-prop-2-ynyloxyacetamide. It has high activity in inhibiting conidial germination, mycelial growth, and spore formation; It also has a good preventive and therapeutic effect on lychee downy mildew (Tang et al., 2011), pepper blight (Siegenthaler and Hansen, 2021), tomato late blight (Chen et al., 2021), and cucumber downy mildew (Liu et al., 2016; Zhang et al., 2015). In China, mandipropamid has been registered in tomato, pepper, potato, lychee, grape, watermelon, and ginseng and has been widely used to control 

ginseng blight. The application of mandipropamid to ginseng will inevitably cause pesticide residue problems in ginseng and the surrounding environment, and the 2008 JMPR established an ADI for mandipropamid of 0-0.2 mg/kg bw/day. It is worth noting the widespread use of mandipropamid whether will have any impact on human health. And in recent years, the problem of pesticide residue has gained increasing attention; therefore, the rational use and risk assessment of mandipropamid is of great significance. (Farha et al., 2016), grapes (Kwon et al., 2008; Malhat and Abdallah, 2012; Xu et al., 2020; Zhang et al., 2014), tomato (Kwon et al., 2008), pepper (Kwon et al., 2008; Zhang et al., 2014), cabbage (Kwon et al., 2008), potato (Kwon et al., 2008; Zhang et al., 2014), watermelon (Zhang et al., 2014), lettuce (Yang et al., 2020), and Cnidium (Dong et al., 2020) are mainly high-performance liquid chromatography (HPLC) and HPCL-tandem mass spectrometry (MS/MS). Moreover, residual behaviour analysis

71 and research on mandipropamid in grapes (Malhat and Abdallah, 2012), lettuce (Yang et al., 2020), and Cnidium (Dong et al., 2020) have been undertaken. However, there have been no systematic studies on the residual behaviour, degradation dynamics, and

74 dietary risk assessment of mandipropamid in ginseng. Therefore, in this study, we

75 established a method for the detection of mandipropamid in ginseng using HPLC-

76 MS/MS. Through field trials at five locations for 1 year, the residual behaviour and 
degradation dynamics of mandipropamid in ginseng were analysed. Additionally, the safety of mandipropamid use on ginseng was evaluated in combination with the Chinese dietary structure. Finally, reasonable suggestions were provided for the rational use of mandipropamid on ginseng, and the basis for the formulation of residue limits in ginseng was provided.

\section{Materials and Methods}

\subsection{Instruments and reagents}

The following materials were used: 1260-6470 HPLC-MS/MS (Agilent

Technologies, USA), SHMADIU Model AUY220 Balance (Shmadiu Corporation, Japan), HUAPUDA Model YXJ-A Centrifugal Machines (Changzhou Huapuda Educational Instrument Corporation, China), Kunshan KQ-500 Ultrasonicator (Kunshan Ultrasonics Corporation, China), and a digital high-speed dispersive homogeniser (IKA T25, IKA Company, Germany).

Analytical standards of mandipropamid (purity 99.5\%, Dr. Ehrenstorfer GmbH, Germany) were used. The mandipropamid standard substance $(0.0101 \mathrm{~g})$ was accurately weighed, diluted to $10 \mathrm{~mL}$ with acetonitrile, sonicated for $10 \mathrm{~min}$, and stored in a refrigerator at $-4^{\circ} \mathrm{C}$. Acetonitrile and methanol were of HPLC grade (MREDA Technology Inc., USA), formic acid was of 96\% HPLC grade (TEDIA Company, USA), ammonium acetate was of $98 \%$ analysis grade (SIGMA, Germany), both sodium chloride and magnesium sulphate were of analytical grade (Beijing 
97 Chemical Plant, China), and Cleanert PSA was of PR grade (Agela Technology,

98 China).

\subsection{Field trial}

\subsubsection{The degradation experiments of mandipropamid in ginseng plant and soil}

101

102

103

104

105

106

107

108

111 Rural Affairs of the People's Republic of China, 2018), the final residue experiments

112 were carried out in Yanji City, Jilin Province, Baishan City, Jilin Province, Huanren

113 Manchu Autonomous County, Liaoning Province, Fusong City, Jilin Province, and

114 Ji'an City, Jilin Province. Three experiments plots were set up, each plot was $50 \mathrm{~m}^{2}$.

115 In the early stage of ginseng blight, the dosage of $900 \mathrm{~mL} / \mathrm{ha}(210.6 \mathrm{~g}$ a.i./ha $)$ was 
116 applied once, and the water was mixed with $600 \mathrm{~kg} / \mathrm{ha}$. Fresh ginseng, ginseng plant

117 and soil samples were collected twice at 14, 21, and 28 days after application.

$118 \quad$ 2.2.3 Sample collection

119 Collection of fresh ginsengs: $2 \mathrm{~kg}$ of normal and disease-free underground fleshy

120 root of ginseng was randomly collected with 12 plots, and the soil attached to ginseng

121 was brushed off with a brush and put into a plastic sealing bag.

123 aboveground parts were randomly collected with 12 plots, cut into $1 \mathrm{~cm}$ size with

124 scissors, and mixed evenly. $500 \mathrm{~g}$ of samples were taken by four methods and put into 125 plastic sealing bags.

126 Collection of ginseng soil: a soil sampler was used to randomly collect ginseng

127 soil samples at five points, and $0-10 \mathrm{~cm}$ deep soil was collected in the degradation

128 experiments, and 0-15 cm deep soil was collected in the final residue experiment.

129 After the collected soil was thoroughly mixed, the impurities such as gravel and sticks

130 were removed and $500 \mathrm{~g}$ samples were taken by quartering method into a plastic

131 sealing bag.

\section{$132 \quad$ 2.2.4 Preparation of samples}

133 Fresh ginseng samples were gently washed using cool water, and the surfaces of the

134 samples were dried indoors. Fresh ginseng samples were baked at $55^{\circ} \mathrm{C}$ for $24 \mathrm{~h}$ to

135 prepare dried ginseng, and fresh ginseng samples were placed in a cage on a pot filled 
136 with water at $80^{\circ} \mathrm{C}$ and heated to boiling for $2.5-3 \mathrm{~h}$. Then, the heated ginseng was

137 cooled and dried at $70^{\circ} \mathrm{C}$ for $6 \mathrm{~h}$ with a dryer. Next, the ginseng was infiltrated with

138 water, and the ginseng was dried again at $55^{\circ} \mathrm{C}$ for $24 \mathrm{~h}$. Ginseng plant samples were

139 placed in a tissue masher, and mashed for 5 min.

\section{$140 \quad 2.3$ Extraction and purification}

141 Next, $5.0( \pm 0.05) \mathrm{g}$ of the homogenised fresh ginseng, dried ginseng, red ginseng,

142 ginseng plant, and ginseng soil samples were added to 50-mL centrifuge tube, and

143 then, $5 \mathrm{~mL}$ of distilled water and $10 \mathrm{~mL}$ of acetonitrile were added to the tube. After

144 standing immersion for $5 \mathrm{~min}$, vortex extraction was performed for $2 \mathrm{~min}$, and the

145 samples were centrifuged at 5,000 $\mathrm{g}$ for $5 \mathrm{~min}$.

146 An aliquot of $1 \mathrm{~mL}$ of the upper layer of fresh ginseng, dried ginseng, red ginseng,

147 and ginseng soil was transferred to a centrifuge tube containing $50 \mathrm{mg}$ PSA and 100

$148 \mathrm{mg}$ anhydrous magnesium sulphate. An aliquot of $1 \mathrm{~mL}$ of the upper layer of the

149 ginseng plant was transferred to a centrifuge tube containing $50 \mathrm{mg}$ PSA, $25 \mathrm{mg}$

$150 \mathrm{GCB}$, and $100 \mathrm{mg}$ anhydrous magnesium sulphate. The mixture was shaken

151 vigorously 100 times and centrifuged for $5 \mathrm{~min}$ at 5,000 rpm. The upper layer was

152 filtered through a $0.22-\mu \mathrm{m}$ nylon syringe filter disc and analysed by HPLC-MS/MS.

\section{$153 \quad 2.4$ Instrumental parameters}

\section{$154 \quad$ 2.4.1 Chromatographic conditions}


$156\left(3.0 \times 100 \mathrm{~mm}, 1.8 \mu \mathrm{m}\right.$ at $\left.30^{\circ} \mathrm{C}\right)$ column. The mobile phase was composed of

157 acetonitrile (A) and water containing $0.1 \%$ formic acid and $5 \mathrm{mmol}$ ammonium

158 acetate (B) with a linear gradient. The gradient elution procedure is shown in Table

159 S1.

$160 \quad 2.4 .2$ Mass spectrometry conditions

161 The ionisation source mode was electrospray ionisation, ionisation source polarity

162 was positive ion mode (ESI+), scanning mode was multiple reaction monitoring,

163 atomising gas was nitrogen, nebuliser gas pressure was $45 \mathrm{psi}$, ion spray voltage was

$1644,000 \mathrm{~V}$, sheath gas temperature was $350^{\circ} \mathrm{C}$, sheath gas was $12 \mathrm{~L} / \mathrm{min}$, quantitative

165 ion of mandipropamid was 412/328.1, qualitative ion of mandipropamid was

$166412 / 328.1$ and 412/124.8, fragmentor was $60 \mathrm{~V}$, and collision energy was 412/328.1

$167(13 \mathrm{~V})$ and $412 / 124.8(35 \mathrm{~V})$

$168 \quad 2.5$ Configuration of standard solutions

169 Accurately weighing $0.0101 \mathrm{~g}$ of mandipropamid standard, using acetonitrile

170 constant volume to $10 \mathrm{~mL}$, prepared with a concentration of $1000 \mathrm{mg} / \mathrm{kg}$ of standard

171 mother liquor, stored in a refrigerator at $-18^{\circ} \mathrm{C}$, shelf life of 6 months. During use,

172 acetonitrile and blank matrix solution were diluted to $0.001,0.002,0.005,0.01,0.02$,

$1730.05,0.1,0.2,0.5 \mathrm{mg} / \mathrm{kg}$, respectively. According to the above instrument conditions, 
174 the injection concentration as horizontal coordinate, linear regression model was

175 established with the peak area as ordinate.

\section{$176 \quad 2.6$ Statistical analysis}

177 In this study, the standard curve and matrix standard curve of the same

178 concentration were detected under the same chromatographic conditions, and the

179 matrix effect (ME) was calculated according to the slope of the two standard

180 solutions. When the matrix effect was within $100 \%( \pm 20)$, it was ignored; when it

181 was greater than $120 \%$, it showed enhancement, and when this was less than $80 \%$, it

182 showed inhibition. The calculation formula is as follows (Fang et al., 2019):

$183 \quad M E(\%)=K_{s} / K_{m} \times 100(1)$

184 where $\mathrm{K}_{\mathrm{S}}$ is the slope of the standard curve and $\mathrm{K}_{\mathrm{m}}$ is the slope of the matrix standard

185 curve.

186 The dissipation dynamics of mandipropamid in ginseng plants and soil were

187 evaluated using first-order kinetics as follows (Fang et al., 2019; Vargas-Pérez et al., 188 2020):

$189 \quad C_{t}=C_{0} \times e^{-K t}(2)$

$190 \quad T_{1 / 2}=\ln 2 / k(3)$

191 where $\mathrm{C}_{\mathrm{t}}(\mathrm{mg} / \mathrm{kg})$ is the residual concentration of mandipropamid in the ginseng plant

192 or soil, $\mathrm{C}_{0}(\mathrm{mg} / \mathrm{kg})$ is the initial concentration of mandipropamid in the ginseng plant

193 or soil, $\mathrm{k}\left(\mathrm{day}^{-1}\right)$ is the dissipation rate constant, and $\mathrm{T}_{1 / 2}$ is the pesticide half-life of 
194 pesticide degradation.

\subsection{Dietary intake risk assessment}

196 Dietary exposure and risk assessments were performed to ensure the rational use of

197 mandipropamid. (Risk Quotient) RQ>100\% indicated that there was an unacceptable

198 risk to human health; the larger the value, the greater the risk. RQ $<100 \%$ indicated

199 that the risk to human health was acceptable; the smaller the value, the smaller the

200 risk.

201 The chronic dietary risk assessment was undertaken by calculating RQ as follows

202 (Fang et al., 2019):

203

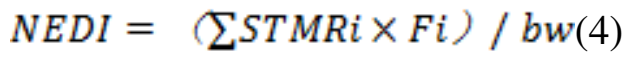

204

$$
R Q=N E D I / A D I \times 100(5)
$$

205 where NEDI $(\mathrm{mg} / \mathrm{kg}, \mathrm{bw})$ is the national estimated daily intake, STMRi $(\mathrm{mg} / \mathrm{kg})$ is the 206 supervised trial median residue level, $\mathrm{Fi}(\mathrm{kg} / \mathrm{d})$ is the average daily food intake, bw

207 (kg) is the average Chinese body weight (63 kg), and ADI (mg/kg, bw) is the 208 acceptable daily intake.

\section{Results and Discussion}

\section{$210 \quad 3.1$ The Optimization of extraction and purification}

211 In this study, the optimization of extraction and purification were conducted before

212 sample testing. Different volumes (10, 15 and $20 \mathrm{~mL}$ ) of Acetonitrile, Methanol, 
213 Ethyl acetate and Acetone were selected for comparison. The result shows the

214 extraction effect of $10 \mathrm{~mL}$ of acetonitrile can meet the recovery requirements and

215 reduce the amount of solvent used. Thus, $10 \mathrm{~mL} 10 \mathrm{~mL}$ of acetonitrile was chosen as

216 the extraction solvent. The most commonly used scavengers for the QuEChERS

217 method are PSA, C18, GCB, and anhydrous MgSO4. We compared the purification

218 effects of different doses of PSA, C18 and GCB and found that $50 \mathrm{mg}$ PSA and 100

219 mg anhydrous magnesium sulphate has good purification effect for all samples. Due

220 to the ginseng plant containing a lot of pigment, add $25 \mathrm{mg} \mathrm{GCB}$ as scavengers to

221 clean up ginseng plant sample.

\subsection{Method validation}

The standard solution was then diluted with acetonitrile and blank matrix solution to

$0.002,0.005,0.01,0.02,0.05,0.1,0.2$, and $0.5 \mathrm{mg} / \mathrm{L}$ series solutions. Instruments

225 detection was performed according to the 2.3 method. With the concentration as the

226 abscissa and the peak area as the vertical coordinates, a standard curve was drawn,

227 resulting in the linear regression equation of mandipropamid. The results are

228 presented in Table 1, the correlation coefficients were all greater than 0.99 . The ME

229 of fresh ginseng, dried ginseng, ginseng plant and soil were within $100( \pm 20 \%)$,

230 indicating that the samples of them can be quantified by standard curve, and the ME

231 of red ginseng was $61.2 \%$, which indicate that red ginseng shown the inhibition for

232 mandipropamid, thus, the samples of red ginseng were quantified by matrix standard

233 curve of red ginseng. 
234 Table 1 The linear regression equation of mandipropamid in different matrices

\begin{tabular}{cccc}
\hline Matrix & Linear regression equation & Coefficient $(\mathrm{R})$ & $\mathrm{ME}(\%)$ \\
\hline Solvent & $\mathrm{y}=103408618.17 \mathrm{x}+1955282.89$ & 0.9854 & $/$ \\
Fresh ginseng & $\mathrm{y}=57171927.30 \mathrm{x}+199740.39$ & 0.9999 & 87.0 \\
Dried ginseng & $\mathrm{y}=66912235.11 \mathrm{x}+20,781.54$ & 0.9996 & 91.7 \\
Red ginseng & $\mathrm{y}=3967045.54 \mathrm{x}-588.30$ & 0.9999 & 61.2 \\
Ginseng plant & $\mathrm{y}=101461225.21 \mathrm{x}+1330231.11$ & 0.9912 & 98.1 \\
Ginseng soil & $\mathrm{y}=85006757.21 \mathrm{x}+653659.39$ & 0.9967 & 99.2 \\
\hline
\end{tabular}

235 Note: ME, Matrix effects.

236 The accuracy and precision of the method were verified using an addition-recovery

237 test. According to the above method, the added amounts of fresh ginseng and soil

238 were $0.01,0.05$, and $0.5 \mathrm{mg} / \mathrm{kg}$, and those of dry ginseng, red ginseng, and plants

239 were $0.01,0.05,0.5$, and $50 \mathrm{mg} / \mathrm{kg}$, respectively. This method was repeated five

240 times. The results are presented in Table 2 . The sensitivity and accuracy of the

241 method met the requirements and were suitable for the residue analysis of

242 mandipropamid in ginseng. 
247 Table 2 The addition recovery rate, RSD, LOQ, and LOD in ginseng

\begin{tabular}{|c|c|c|c|c|c|}
\hline Matrix & $\begin{array}{l}\text { Spiked level } \\
\text { (mg/kg) }\end{array}$ & $\begin{array}{l}\text { Average Recovery } \\
\qquad(\%)\end{array}$ & $\begin{array}{l}\text { RSD } \\
(\%)\end{array}$ & $\begin{array}{c}\text { LOQ } \\
(\mathrm{mg} / \mathrm{kg})\end{array}$ & $\begin{array}{c}\text { LOD } \\
(\mathrm{mg} / \mathrm{kg})\end{array}$ \\
\hline \multirow{3}{*}{$\begin{array}{l}\text { Fresh } \\
\text { ginseng }\end{array}$} & 0.01 & 89.9 & 10.1 & \multirow{18}{*}{0.01} & \multirow{3}{*}{$4.3 \times 10^{-4}$} \\
\hline & 0.05 & 87.4 & 4.0 & & \\
\hline & 0.5 & 96.3 & 1.7 & & \\
\hline \multirow{4}{*}{$\begin{array}{l}\text { Dried } \\
\text { ginseng }\end{array}$} & 0.01 & 96.1 & 1.3 & & \multirow{4}{*}{$3.6 \times 10^{-4}$} \\
\hline & 0.05 & 99.0 & 1.8 & & \\
\hline & 0.5 & 101.6 & 2.8 & & \\
\hline & 50 & 95.7 & 1.4 & & \\
\hline \multirow{4}{*}{$\begin{array}{c}\text { Red } \\
\text { ginseng }\end{array}$} & 0.01 & 92.6 & 3.6 & & \multirow{4}{*}{$4.8 \times 10^{-4}$} \\
\hline & 0.05 & 98.7 & 3.1 & & \\
\hline & 0.5 & 100.0 & 1.4 & & \\
\hline & 50 & 100.1 & 2.7 & & \\
\hline \multirow{4}{*}{$\begin{array}{l}\text { Ginseng } \\
\text { plant }\end{array}$} & 0.01 & 89.6 & 2.4 & & \multirow{4}{*}{$4.1 \times 10^{-4}$} \\
\hline & 0.05 & 99.1 & 2.4 & & \\
\hline & 0.5 & 94.2 & 1.9 & & \\
\hline & 50 & 95.8 & 2.2 & & \\
\hline \multirow{3}{*}{$\begin{array}{l}\text { Ginseng } \\
\text { soil }\end{array}$} & 0.01 & 97.3 & 1.1 & & \multirow{3}{*}{$3.9 \times 10^{-4}$} \\
\hline & 0.05 & 93.7 & 1.2 & & \\
\hline & 0.5 & 96.8 & 1.5 & & \\
\hline
\end{tabular}

248 Note: RSD, relative standard deviation; LOQ, limit of quantitation; LOD, limit of 249 etection.

$250 \quad 3.3$ The degradation dynamics of mandipropamid in ginseng plant and soil

251 The samples of ginseng plant and soil were detected using the 2.3-2.4 methods, the 252 degradation of mandipropamid conformed to first-order kinetics. The content of 
mandipropamid in ginseng plant and soil $2 \mathrm{~h}$ after application was that of the initial

254 residues, and as time passed, the residue concentration of mandipropamid gradually

255 decreased. The results are shown in Figure 1-2 and Table 3. The half-life of

256 mandipropamid in ginseng plant was 13.8 (Fusong), 28.0 (Huanren), and $13.9 \mathrm{~d}$

257 (Baishan). The initial residue amounts of mandipropamid in ginseng plant were 5.24

258 (Fuosng), 3.22 (Huanren), and $4.42 \mathrm{mg} / \mathrm{kg}$ (Baishan). The half-life of mandipropamid

259 in ginseng plant was 9.8 (Fusong), 16.0 (Huanren), and 27.4 d (Baishan). The initial

260 residue amount of mandipropamid in ginseng plants was 0.039 (Fuosng), 0.054

261 (Huanren), and $0.068 \mathrm{mg} / \mathrm{kg}$ (Baishan). The difference in the initial residues may be

262 due to multiple factors, such as plant growth status and weather conditions

263 (temperature, humidity, wind speed, etc.) at the test point during spraying. The results

264 showed that the half-life of mandipropamid in ginseng plants was not significantly

265 different in Fusong and Baishan, whereas that in Huanren was significantly higher

266 than that in Fusong and Baishan, mainly due to plant size, sparseness, and metabolic

267 capacity, which may also be affected by factors such as plant variety and weather

268 conditions (Bai et al., 2020). The half-life of mandipropamid in ginseng soil was

269 different in Fusong, Huanren, and Baishan. Since before ginseng planting, the soil

270 was artificially mixed with some other substances such as sand, its organic matter

271 content varied between locations. The organic acid content of Baishan soil was 4\%,

272 that of Fusong soil was $4.3 \%$, that of Huanren soil was 4.4\%, and Baishan soil had the

273 lowest organic matter content. This may be responsible for the half-life of 
274 mandipropamid in Baishan soil, which was significantly higher than that of the other

275 two locations, possibly because of to the effects of factors such as the types of

276 microorganisms in the soil, temperature and humidity of the environment, and

277 duration of sunshine.

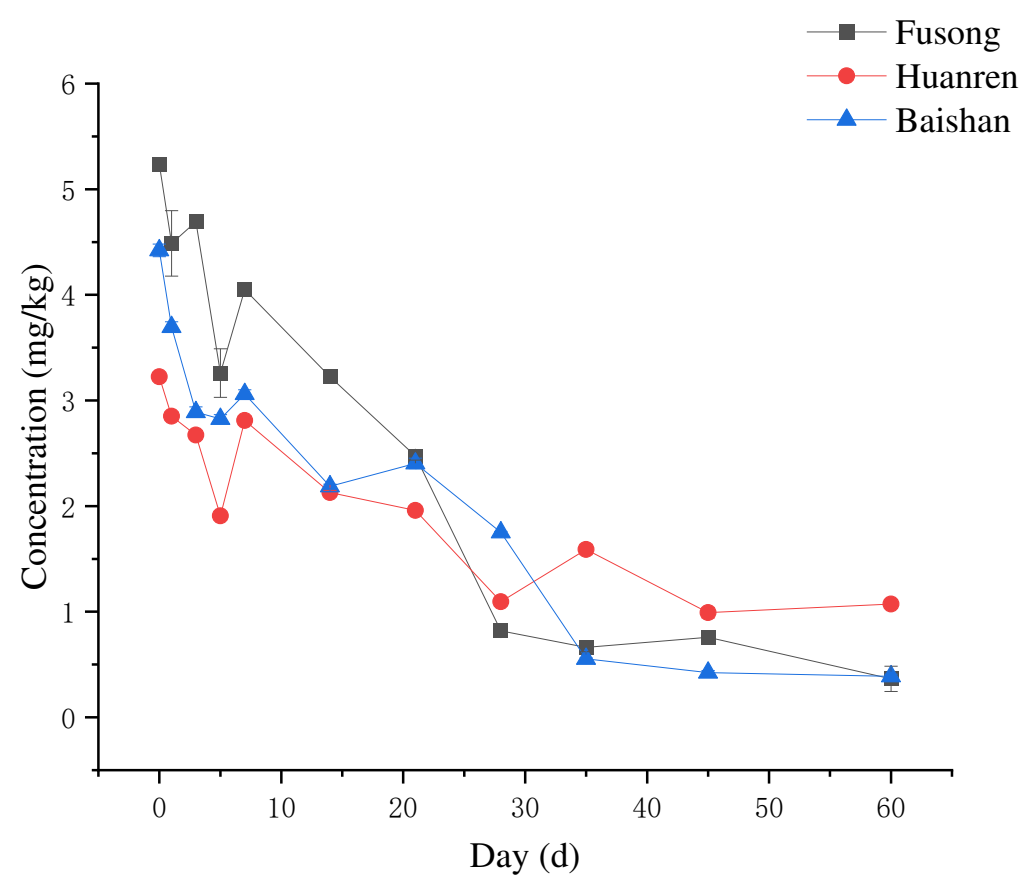

278

279 Figure 1 The degradation dynamics curve of mandipropamid in ginseng plant 


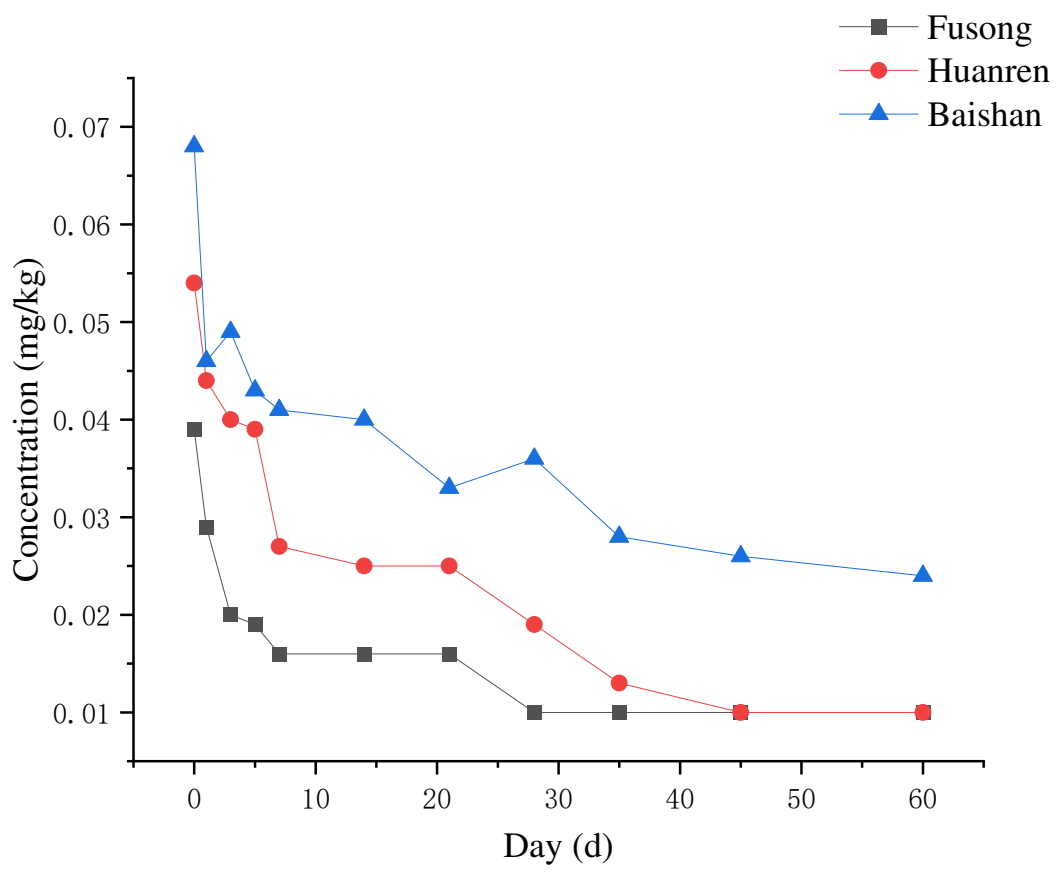

281 Figure 2 The degradation dynamics curve of mandipropamid in ginseng soil

282 Table 3 The degradation dynamics of mandipropamid in ginseng plant and soil

\begin{tabular}{ccccc}
\hline Matrix & Location & Equation & Coefficient $\left(\mathrm{R}^{2}\right)$ & Half-life $\left(\mathrm{T}_{1 / 2}\right)$ \\
\hline \multirow{2}{*}{ Ginseng plant } & Huansong & $\mathrm{C}_{\mathrm{t}}=4.9394 \mathrm{e}^{-0.046 \mathrm{t}}$ & 0.9377 & 13.8 \\
& Baishan & $\mathrm{C}_{\mathrm{t}}=2.7426 \mathrm{e}^{-0.019 \mathrm{t}}$ & 0.8217 & 28.0 \\
& & $\mathrm{C}_{\mathrm{t}}=3.9597 \mathrm{e}^{-0.042 \mathrm{t}}$ & 0.9043 & 13.9 \\
& Fusong & $\mathrm{C}_{\mathrm{t}}=0.0235 \mathrm{e}^{-0.019 \mathrm{t}}$ & 0.6379 & 9.8 \\
Ginseng soil & Huanren & $\mathrm{C}_{\mathrm{t}}=0.0423 \mathrm{e}^{-0.028 \mathrm{t}}$ & 0.9024 & 16.0 \\
& & & & \\
& Baishan & $\mathrm{C}_{\mathrm{t}}=0.0499 \mathrm{e}^{-0.014 t}$ & 0.7488 & 27.4 \\
\hline
\end{tabular}

\subsection{Final residues of mandipropamid in ginseng}

284 Based on the design of the field experiment, the final residues of mandipropamid in

285 fresh ginseng, dried ginseng, red ginseng, ginseng plant, and ginseng soil in Fusong 
286 County, Jilin Province, Huanren Manchu Autonomous County in Liaoning Province,

287 Baishan City in Jilin Province, Ji'an City in Jilin Province, and Yanbian City in Jilin

288 Province were collected. The results obtained using the above-described methods are

289 shown in Table 4. The residual amounts of mandipropamid were as follows: fresh

290 ginseng, <0.01-0.185; dried ginseng, <0.01-0.265; red ginseng, 0.085-1.544; ginseng

291 plant, 0.075-4.800; and ginseng soil, $<0.01-0.014 \mathrm{mg} / \mathrm{kg}$. The final residual amount

292 of mandipropamid in ginseng showed an insignificant decreasing trend with time,

293 which may be affected by the application time, crop varieties, weather, and other

294 factors. The STMR of mandipropamid was $<0.01,0.019$, and $0.295 \mathrm{mg} / \mathrm{kg}$ in fresh,

295 dried, and red ginseng, respectively. The HRs of mandipropamid in fresh, dried, and

296 red ginseng were $0.185,0.265$, and $1.544 \mathrm{mg} / \mathrm{kg}$, respectively. At present, China has

297 not established the maximum residue limit (MRL) of mandipropamid in ginseng,

298 partly because of the lack of mandipropamid residue and digestion data available for

299 ginseng. The results of this study provide a basis for the rational use of

300 mandipropamid in ginseng and help establish the MRL of mandipropamid in ginseng. 
301 Table 4 Final residues of mandipropamid in ginseng with different application dosages and times

\begin{tabular}{|c|c|c|c|c|c|c|}
\hline Sample & $\begin{array}{l}\text { Does } \\
\text { (g a.i./ha) }\end{array}$ & Times & PHI & Residue data $(\mathrm{n}=3)($ Mean value, $\mathrm{mg} / \mathrm{kg})$ & $\begin{array}{l}\text { STMR } \\
(\mathrm{mg} / \mathrm{kg})\end{array}$ & $\begin{array}{c}\mathrm{HR} \\
(\mathrm{mg} / \mathrm{kg}) \\
\end{array}$ \\
\hline \multirow{4}{*}{ Fresh ginseng } & \multirow{3}{*}{210.6} & \multirow{3}{*}{1} & 14 & $<0.01(6), 0.034,0.035,0.067,0.185$ & \multirow{3}{*}{$<0.01$} & \multirow{3}{*}{0.185} \\
\hline & & & 21 & $<0.01(8), 0.033,0.033$ & & \\
\hline & & & 28 & $<0.01(7), 0.016,0.068,0.069$ & & \\
\hline & \multirow{3}{*}{210.6} & \multirow{3}{*}{1} & 14 & $<0.01,0.012,0.012,0.012,0.017,0.019,0.099,0.100,0.222,0.231$ & \multirow{3}{*}{0.019} & \multirow{3}{*}{0.265} \\
\hline \multirow[t]{2}{*}{ Dried ginseng } & & & 21 & $0.011,0.011,0.015,0.015,0.024,0.024,0.031,0.035,0.157,0.157$ & & \\
\hline & & & 28 & $0.006,0.007,0.016,0.017,0.018,0.018,0.021,0.021,0.211,0.265$ & & \\
\hline \multirow{3}{*}{ Red ginseng } & \multirow{3}{*}{210.6} & \multirow{3}{*}{1} & 14 & $0.085,0.091,0.092,0.100,0.236,0.243,0.255,0.303,1.896,1.901$ & \multirow{3}{*}{0.295} & \multirow{3}{*}{1.544} \\
\hline & & & 21 & $0.164,0.179,0.182,0.289,0.300,0.310,0.380,0.390,1.534,1.544$ & & \\
\hline & & & 28 & $0.112,0.116,0.133,0.146,0.457,0.462,0.479,0.487,1.432,1.452$ & & \\
\hline \multirow{3}{*}{ Ginseng plant } & \multirow{3}{*}{210.6} & \multirow{3}{*}{1} & 14 & $0.075,0.078,0.223,0.235,1.250,1.255,1.632,1.662,4.643,4.800$ & \multirow{3}{*}{0.729} & \multirow{3}{*}{4.800} \\
\hline & & & 21 & $0.177,0.192,0.500,0.623,0.689,0.694,0.938,0.973,2.005,2.007$ & & \\
\hline & & & 28 & $0.389,0.466,0.466,0.476,0.578,0.763,0.847,0.872,1.604,1.635$ & & \\
\hline \multirow{3}{*}{ Ginseng soil } & \multirow{3}{*}{210.6} & \multirow{3}{*}{1} & 14 & $<0.01(10)$ & \multirow{3}{*}{$<0.01$} & \multirow{3}{*}{0.014} \\
\hline & & & 21 & $<0.01(8), 0.014,0.014$ & & \\
\hline & & & 28 & $<0.01(8), 0.012,0.012$ & & \\
\hline
\end{tabular}

Note: PHI, Preharvest interval; STMR, supervised trials median residue; HR, highest residue. 


\subsection{Dietary risk assessment}

The chronic dietary exposure risk assessment is based on the Chinese dietary structure, combined with the registered crops and corresponding STMRi values and the daily allowable intake of mandipropamid to calculate the RQ for evaluation. At

307 present, mandipropamid has been registered in China for tomato, pepper, lychee,

308 potato, grape, ginseng, and watermelon. According to the principle of maximum risk,

309 the largest MRL value in the food group was selected for evaluation, and the largest

310 MRL value was selected according to the following priority order:

311 China $>$ CAC $>$ United States $>$ EU $>$ South Korea $>$ Japan $>$ Australia, according to the

312 "National Food Safety Standard Maximum Residue Limits of Pesticides in Food"

313 (National Health Commission of the People's Republic of China, 2019). The ADI of

314 mandipropamid is $0.2 \mathrm{mg} / \mathrm{kg}$ bw.

315 The maximum STMRi value of mandipropamid in fresh, dried, and red ginseng was

316 selected as the reference limit for chronic dietary risk assessment. Ginseng is

317 classified as soy sauce, and the STMRi of mandipropamid in red ginseng is regarded

318 as the residue of soy sauce. The results are shown in Table 5, where the median RQ

319 value is $2.9 \%$, which is far less than $100 \%$, indicating that the chronic dietary risk of

320 mandipropamid use on ginseng is acceptable, and the recommended dose will not

321 cause unacceptable risks to Chinese consumers. 
322 Table 5 The Chinese dietary pattern and risk probability of mandipropamid in ginseng

\begin{tabular}{|c|c|c|c|c|c|c|}
\hline Food & & esidue data & & & & \\
\hline classification & $\mathrm{Fi}(\mathrm{kg})$ & $(\mathrm{mg} / \mathrm{kg})$ & Sources & NEDI (mg) & ADI (mg) & RQ \% \\
\hline Tubers & 0.0495 & 0.01 & China & $7.86 \times 10^{-6}$ & & \\
\hline Dark vegetables & 0.0915 & 3 & China & $4.36 \times 10^{-3}$ & & \\
\hline Fruits & 0.0457 & 2 & China & $1.45 \times 10^{-3}$ & $0.2 \times 63$ & 2.9 \\
\hline Soy sauce & 0.009 & 0.295 & STMR & $4.21 \times 10^{-5}$ & & \\
\hline Total & 1.0286 & & & $5.86 \times 10^{-3}$ & & \\
\hline
\end{tabular}

Note: Fi, Fi, dietary reference intake for a certain kind of food of healthy Chinese people; STMR is the supervised trials median residue of

mandipropamid with a pre-harvest interval RQ, chronic dietary exposure risk probability. 
325

326

327

\section{Conclusion}

In this study, an HPLC-MS/MS method was established for the detection of mandipropamid in ginseng, and the degradation dynamics, residue dissipation, and dietary risk assessment of mandipropamid in ginseng were studied under field application. This method has good precision and accuracy. The residues in fresh ginseng, dried ginseng, red ginseng, ginseng plant, and ginseng soil were $<0.01-$ $0.185,<0.01-0.265,0.085-1.544,0.075-4.800$, and $<0.01-0.014 \mathrm{mg} / \mathrm{kg}$, respectively. The half-lives of mandipropamid in ginseng plant and soil were 13.8-28.0 and 9.8$27.4 \mathrm{~d}$, respectively. According to the final residual test results, after one application, the chronic dietary risk of mandipropamid in ginseng was an RQ value of $2.9 \%$, which was far less than $100 \%$, indicating that there was no significant potential risk of mandipropamid in ginseng at the recommended dose. This study provides a basis for the rational use of mandipropamid in ginseng, as well as a reference for the establishment of MRL of mandipropamid in ginseng.

Authors Contributions Zhiguang Hou performed interpretation, Writing, Review and Editing.

Xingang Hou performed the data analyses and manuscript preparation and wrote the manuscript.

Liping Wei performed the experiments of field experiments and sample collection section.

Zhanwen Cao performed the experiments of field experiments and sample 
346 collection section.

347 Zhou Lu performed the analysis with constructive discussions.

348 Hanju Liu performed the experiments of field experiments and sample collection

349 section.

350 Zhongbin Lu contributed to the conception of the study and provided assistance

351 through all the experiments.

352 Funding Partial funding was received from the Agricultural Industry Standard of the

353 Chinese Ministry of Agriculture (2018) (grant no.: 181721301092371097) and the

354 Special Fund for Ginseng Industry Development of Jilin Province (2015) (grant no.:

355 201501).

356 Data availability All data generated or analyzed during this study are included in this 357 published article [and its supplementary information files]

\section{Compliance with ethical standards}

359 Ethics approval and consent to participate Not applicable

360 Consent for publication Not applicable

361 Competing interests The authors declare that they have no competing interests

\section{References}

363 Bai, A., Chen, A., Chen, W., et al., 2020. Study on degradation behaviour, residue

364 distribution, and dietary risk assessment of propiconazole in celery and onion under

365 field application [J]. J. Sci. Food Agric. https://doi.org/10.1002/jsfa.10817. 
366 Chen, J., Tian, B.H., Lai, R.L., et al., 2021. Field efficacy of new mixtures of

367 oxathiapiprolin-mandipropamid 26\% SC against to late blight [J]. Agrochemicals 368 60(02), 154-156.

369 Dong, K. J., Jeong, W. M., Goo, Y. M., et al., 2020. Study on residual characteristics 370 of mandipropamid and metalaxyl-M in Cnidium officinale Makino [J]. The Korean 371 Journal of Pesticide Science, 2020, 24(2), 172-179.

372 Fang, Q., Wu, R., Hu, G., et al., 2019. Dissipation behavior, residue distribution and 373 risk assessment of three fungicides in pears [J]. J. Sci. Food Agric. 100(4).

374 Fan, S., Zhang, Z., Su, H., et al., 2020. Panax ginseng clinical trials: Current status 375 and future perspectives [J]. Biomed. Pharmacother. 132, 110832.

376 Farha, W., Rahman, M.M., El-Aty, A.A., et al., 2016. Analysis of mandipropamid 377 residual levels through systematic method optimization against the matrix complexity 378 of sesame leaves using HPLC/UVD [J]. Biomed. Chromatogr. 30(7), 990-995.

379 He, Y., 2008. Mandipropamid; Department of Science and Education, Ministry of 380 Agriculture, China [Online]. Available at:

381 http://www.fao.org/agriculture/crops/thematic-sitemap/theme/pests/lpe/lpe-m/en/

382 Kwon, C.H., Chang, M.I., Im, M.H., et al., 2008. Determination of mandipropamid 383 residues in agricultural commodities using high-performance liquid chromatography 384 with mass spectrometry [J]. Analytical Science \& Technology 21(6), 518-525. 
385 Liu, D., Wang, X.M., Hou, Z.G., et al., 2016. Toxicological test and field efficacy of 386 fungicides to Pseudoperonospora cubensis [J]. Agrochemicals 55(05), 377-379+386.

387 Malhat, F.M., Abdallah, H., 2012. Dissipation and residues of mandipropamid in 388 grape using QuEChERS methodology and HPLC-DAD [J]. Isrn Analytical Chemistry $3892012(1), 5$.

390 Ministry of Agriculture and Rural Affairs of the People's Republic of China, NY/788-

3912018 Guideline for the testing of pesticide residues in corps [Z]. 2018.

392 National Health Commission of the People's Republic of China, National food safety 393 standard-Maximum residue limits for pesticides in food: GB 2763-2019 [S]. 2019.

394 Park, T.Y., Hong, M., Sung, H., et al., 2017. Effect of Korean red ginseng in chronic 395 liver disease [J]. J. Ginseng Res. 2017, 41(4), 450-455.

396 Vargas-Pérez, M., González, F.J.E., Frenich, A. G., 2020. Dissipation and residue 397 determination of fluopyram and its metabolites in greenhouse crops [J]. Journal of the. 398 Science of. Food and Agriculture. 2020, 100(13).

399 Siegenthaler, T.B., Hansen, Z., 2021. Sensitivity of Phytophthora capsici from

400 Tennessee to mefenoxam, fluopicolide, oxathiapiprolin, dimethomorph,

401 mandipropamid, and cyazofamid [J]. Plant Dis. https://doi.org/10.1094/PDIS-08-20402 1805-RE. 
403 404 405 406 407 408 409 410 417 MS/MS [J]. J. Sep. Sci. 37(3), 211-218.

418 Zhang, N., Huang, X., Guo, Y.L., et al., 2021. Evaluation of storage period of fresh 419 ginseng for quality improvement of dried and red processed varieties [J]. J. Ginseng 420

Tang, Z.-H., Wang, et al., 2011. Baseline and differential sensitivity to mandipropamid among isolates of Peronophythora litchii, the causal agent of downy blight on litchi[J]. Crop Protection Guildford, 2011, 3: 354-359.

Xu, G., Jia, X., Zhang, H., et al., 2020. Enantioselective fate of mandipropamid in grape and during processing of grape wine [J]. Environ. Sci. Pollut. Res. 27(32), 40148-40155.

Yang, S.H., Lee, J.I., Choi, H., 2020. Dissipation characteristics of mandipropamid and thiamethoxam for establishment of pre-harvest residue limits in lettuce [J]. J. Appl. Biol. Chem. 63(3), 267-274.

Zhang, B., Zhao, W., Zhang, Y. L., et al., 2015. Control effect of five kinds of preparations and combinations of cucumber downy mildew and its evaluation $[\mathrm{J}]$., Agrochemical, 2015,54(06), :456-457+468.

Hu, Zhang, H., Xiang, et al., 2014. Enantioselective determination of carboxyl acid amide fungicide mandipropamid in vegetables and fruits by chiral LC coupled with Res. https://doi.org/10.1016/j.jgr.2021.06.007. 


\section{Supplementary Files}

This is a list of supplementary files associated with this preprint. Click to download.

- SupplementaryMaterial.docx 